\title{
Junior doctors' early career choices do not predict career destination in neurology: 40 years of surveys of UK medical graduates
}

\author{
Atena Barat, Michael J. Goldacre and Trevor W. Lambert *D
}

\begin{abstract}
Background: The rapidly rising rates of brain diseases due to the growing ageing population and the explosion in treatment options for many neurological conditions increase the demand for neurologists. We report trends in doctors' career choices for neurology; investigate factors driving their choices; and compare doctors' original choices with their specialty destinations.

Methods: A multi-cohort, multi-purpose nation-wide study using both online and postal questionnaires collected data on career choice, influencing factors, and career destinations. UK-trained doctors completed questionnaires at one, three, five, and ten years after qualification. They were classified into three groups: graduates of 1974-1983, graduates of 1993-2002, and graduates of 2005-2015.

Results: Neurology was more popular among graduates of 2005-2015 than earlier graduates; however, its attraction for graduates of 2005-2015 doctors reduced over time from graduation. A higher percentage of men than women doctors chose neurology as their first career choice. For instance, among graduates of 2005-2015, $2.2 \%$ of men and $1.1 \%$ of women preferred neurology as first choice in year 1 . The most influential factor on career choice was "enthusiasm for and commitment to the specialty" in all cohorts and all years after graduation. Only $39 \%$ who chose neurology in year 1 progressed to become neurologists later. Conversely, only $28 \%$ of practicing neurologists in our study had decided to become neurologists in their first year after qualification. By year 3 this figure had risen to $65 \%$, and by year 5 to $76 \%$.

Conclusions: Career decision-making among UK medical graduates is complicated. Early choices for neurology were not highly predictive of career destinations. Some influential factors in this process were identified. Improving mentoring programmes to support medical graduates, provide career counselling, develop professionalism, and increase their interest in neurology were suggested.
\end{abstract}

Keywords: Neurology, Physicians, Junior, Career choice, Workforce, Medical, Medical education

\section{Background}

As neurology is a medical specialty involving the diagnosis and treatment of patients with disorders of the nervous system [1], the demand for neurologists is growing faster than supply as a result of demographic changes which have increased the number of older individuals with degenerative neurological conditions; of accelerated progress in science, including

\footnotetext{
* Correspondence: trevor.lambert@dph.ox.ac.uk

UK Medical Careers Research Group, Unit of Health-Care Epidemiology,

Nuffield Department of Population Health, University of Oxford, Old Road

Campus, Oxford OX3 7LF, UK
}

C) The Author(s). 2019 Open Access This article is distributed under the terms of the Creative Commons Attribution 4.0 International License (http://creativecommons.org/licenses/by/4.0/), which permits unrestricted use, distribution, and reproduction in any medium, provided you give appropriate credit to the original author(s) and the source, provide a link to the Creative Commons license, and indicate if changes were made. The Creative Commons Public Domain Dedication waiver (http://creativecommons.org/publicdomain/zero/1.0/) applies to the data made available in this article, unless otherwise stated. vention of advanced techniques for making a precise diagnosis; and the advent of subspecialisations within neurology [2].

According to a World Health Organisation report, in 2017 Europe had the highest median number of neurologists per 100,000 population (9.0) [3]. In 2014, the UK had 1.2 consultant neurologists per 100,000 population [4]. In comparison, it was estimated that 16,366 neurologists were practising in the US in 2012, with a neurologist to population ratio of 5.2 per 100 , 000 [5]. 
Previous research showed several positive factors which can increase student recruitment into neurology, such as an interest in helping people [6], the doctors' parents' education level [7], effective mentorship [7-9], prior specialty experience [9, 10], early exposure to neurosciences [7] and the therapeutic bond between patient and doctor as a result of the chronic nature of neurological diseases [11]. In contrast, medical graduates' interest in neurology can be deterred by financial considerations (e.g. personal debt and annual income) and 'neurophobia' [7]. Neurophobia is ascribed to deficiencies in medical education and is characterised by a fear of neuroscience and neurology due to the greater perceived difficulty of neuroscience and of neurological differential diagnosis compared to other specialties [10].

Understanding the factors which influence UK medical graduates' decisions to choose neurology as their future career, and changes in their decisions, has a pivotal role in education and professional policies. The NHS, government agencies, specialist societies and medical Royal Colleges need to know about intending neurologists' career choices and to make decisions about how to attract, select and retain these doctors, but at present such decisions lack an evidence base. The aims of the present paper were to report trends in medical graduates' aspirations for a career in neurology; to identify factors influencing their choices for neurology; and to identify changes in their career pathway from their early choices to their eventual specialty destination. Such findings may help inform workforce planners to promote the recruitment, training and supply of the medical workforce in neurology.

It is worthwhile to note that this paper is one of a series of papers on individual specialties including anaesthesia [12], surgery [13], and cardiology [14] which are generated from our cohorts.

\section{Methods}

\section{Aim, design, setting and participants}

National longitudinal surveys were conducted by the UK Medical Careers Research Group from 1974 to 2015, collecting data contemporaneously through postal or web questionnaires from the UK medical graduates of $1974,1977,1980,1983,1993,1996$, 1999, 2000, 2002, 2005, 2008, 2009, 2011, 2012, and 2015. As the eligibility criterion for inclusion in the surveys is being a registered doctor, subjects' contact details were provided by the General Medical Council (GMC) with whom all doctors who wish to practise in the UK must be registered.

The surveys used a multi-purpose questionnaire at different time slots: 1,3 , and 5 years after primary medical qualification (graduation from medical school) and at longer intervals thereafter. This paper focuses on three concepts: early career preferences for eventual specialty, factors influencing career preferences, and career specialty destinations. Data on career preferences and influencing factors was analysed from surveys of doctors 1,3 , and 5 years after graduation, using, respectively, 15 cohorts (1974-2015), 12 cohorts (1974-2008 and 2012), and 10 cohorts (1974-1980 and 1993-2008). Data on career destinations was collected from the doctors 10 years after graduation, using 5 cohorts (1993-2002).

Participation was voluntary and required completing a self-administered questionnaire. To maximise the response rate, all non-respondents received up to four paper or email reminders over the ensuing months following the initial contact.

Further details of the research method are presented elsewhere [15].

\section{Research instrument}

The content of the research instrument has been established in usage over many years. Broadly, the questions explored demographic information, career choices and plans, and employment history.

The questionnaire utilised structured questions, for example: "What is your choice of long-term career?" Respondents were invited to specify up to three choices of specialty for their future career in order of preference, identifying choices of equal preference (referred to as "tied choices"). In other words, a tied neurology first choice means that a participant's first choice was to follow either neurology or another named specialty. Then, we asked whether their choice of specialty is "definite", "probable" or "uncertain". They were also asked to specify the importance of each of 13 listed factors in influencing their specialty choice: "not at all", "a little" or "a great deal".

\section{Statistical analyses}

For simplicity, in most tables we combined data on choices into three cohort groups: graduates of 19741983, graduates of 1993-2002, and graduates of 20052015.

All data were processed and analysed using IBM SPSS Statistics for Windows, V22 [16] and Microsoft Excel (2010). We assessed the association between binary or unordered categorical variables by univariate analysis with $\chi^{2}$ tests. To identify linear trends over cohorts, the Mantel-Haenszel linear-by-linear $X^{2}$ test was applied. In this paper, $95 \%$ confidence intervals were quoted for the main results. 


\section{Results}

\section{Response rate}

The response rates for cohorts included in this paper were $56.9 \%(40,412 / 71,026)$ in the first year after graduation, $62.3 \%(31,466 / 50,477)$ in year 3 and $55.4 \%$ (24, $970 / 45,071)$ in year 5 .

\section{First choice of neurology one, three and five years after graduation}

Over all cohorts combined, in years 1,3 , and 5 respectively, $1.0,0.9$, and $0.9 \%$ of responders made neurology their first choice. In year 1 there was a substantial linear increase in choices for neurology across the cohort groupings: only $0.6 \%$ of the graduates of $1974-1983$ chose neurology, compared with $0.9 \%$ of the graduates of 1993-2002 and 1.5\% of the graduates of 2005-2015. In years 3 and 5 this trend was less evident, though graduates from the year 1993 onwards showed a higher level of choices for neurology than did those of 1974-83. Table 1 shows comparative figures and the results of statistical comparisons.

There were large differences between the percentages of men and of women who chose neurology, in all the cohort groupings. For example, in year 1 among the graduates of 2005-2015, 1.1\% (CI: 0.9 to $1.3 \%$ ) of women chose neurology as their first choice compared with $2.2 \%$ (1.8 to $2.6 \%$ ) of men. For years 3 and 5 respectively the corresponding figures for the most recent cohort group were: year 3 women $0.7 \%$ (0.5 to $1.0 \%)$, men $1.1 \%$ ( 0.8 to $1.6 \%)$; year 5 women $0.8 \%$ (0.5 to $1.2 \%)$, men $1.0 \%$ (0.7 to $1.6 \%)$. Figure 1 illustrates the level of first choices for neurology of men and women in each cohort grouping, at years 1, 3, and 5. Conventional $95 \%$ confidence intervals are shown on the figure as a guide to assessing the significance of the male-female differences.

Appendix: Figure 2 shows the corresponding results for men and women who made any choice for neurology - in other words not solely first choices, but also including those who made neurology their second or third choice.

For the most recently surveyed individual cohorts, we present Additional file 1: Table S1 (see Appendix) showing the percentages who chose neurology in each cohort survey. Year 1 first choices varied from 1.2\% in the 2012 and 2015 cohorts to $2.0 \%$ in the 2009 cohort. For the cohorts surveyed, year 3 and year 5 choices also showed large variation from cohort to cohort.

Table 2 compares the level of certainty of career choice between doctors who chose neurology as their first choice with those who chose other hospital physician specialties. In Year 1, 19.7\% of those who considered neurology as their first choice were definite about their decision. Their certainty rose to $32.9 \%$ and $67.4 \%$ in years 3 and 5, respectively. This trend was less pronounced among participants whose first choice was another hospital physician specialty: in year 1 their certainty of career choice was $12.7 \%$ (significantly less than those who chose neurology, $p<.001)$, but it increased in years 3 and 5 (to $25.3 \%$ and then to $60.7 \%$ ). In all years, there was no significant difference between male and female doctors in the level of their certainty about neurology as their first career choice $(p>0.01$ using $X^{2}$ test).

\section{Influencing factors on career choice}

Thirteen possible influencing factors on doctors' career choice were identified by reviewing available literature. Table 3 reflects the responses of participants regarding factors with a great deal of influence on their career choice.

"Enthusiasm/commitment: what I really want to do" was considered as the most influential factor on career choice among all participants (i.e. those choosing neurology or other hospital physician specialties as their first choice of eventual career) although the intending neurologists did not score substantially higher than others on "enthusiasm/commitment" in any of 1,3 , and 5 years after graduation.

The second influential factor for doctors who chose neurology was "student experience of subject" (50.6\%) in year 1, "self-appraisal of own skills/aptitudes" (58.3\%) in year 3 and "experience of jobs so far" (63.6\%) in year 5 after graduation. For respondents who chose other hospital physician specialties "experience of jobs so far" was their second most influential factor, with increasing importance, in year 1 (51.3\%), 3 (58.5\%) and 5 (65.4\%) after graduation.

Table 1 Trends among UK medical graduates in early first choices for eventual careers in neurology

\begin{tabular}{|c|c|c|c|c|c|c|}
\hline \multirow{2}{*}{$\begin{array}{l}\text { Year after } \\
\text { graduation }\end{array}$} & \multicolumn{4}{|c|}{ Cohorts (years of graduation) } & \multicolumn{2}{|l|}{ Statistical tests } \\
\hline & 1974-1983 & 1993-2002 & $2005-2015$ & All cohorts & Linear trend $\left(X^{2}, p\right)$ & Heterogeneity $\left(x_{2}^{2}, p\right)$ \\
\hline Year 1 & $0.6 \%$ & $0.9 \%$ & $1.5 \%$ & $1.0 \%$ & $49.8,<0.001$ & $52.6,<0.001$ \\
\hline Year 3 & $0.7 \%$ & $1.1 \%$ & $0.9 \%$ & $0.9 \%$ & $2.9,0.09$ & $11.9,0.003$ \\
\hline Year 5 & $0.7 \%$ & $1.0 \%$ & $0.9 \%$ & $0.9 \%$ & $1.0,0.32$ & $2.8,0.25$ \\
\hline
\end{tabular}

For doctors surveyed one, three and five years after graduation the table shows the percentages of doctors who specified neurology as their first choice of eventual specialty 

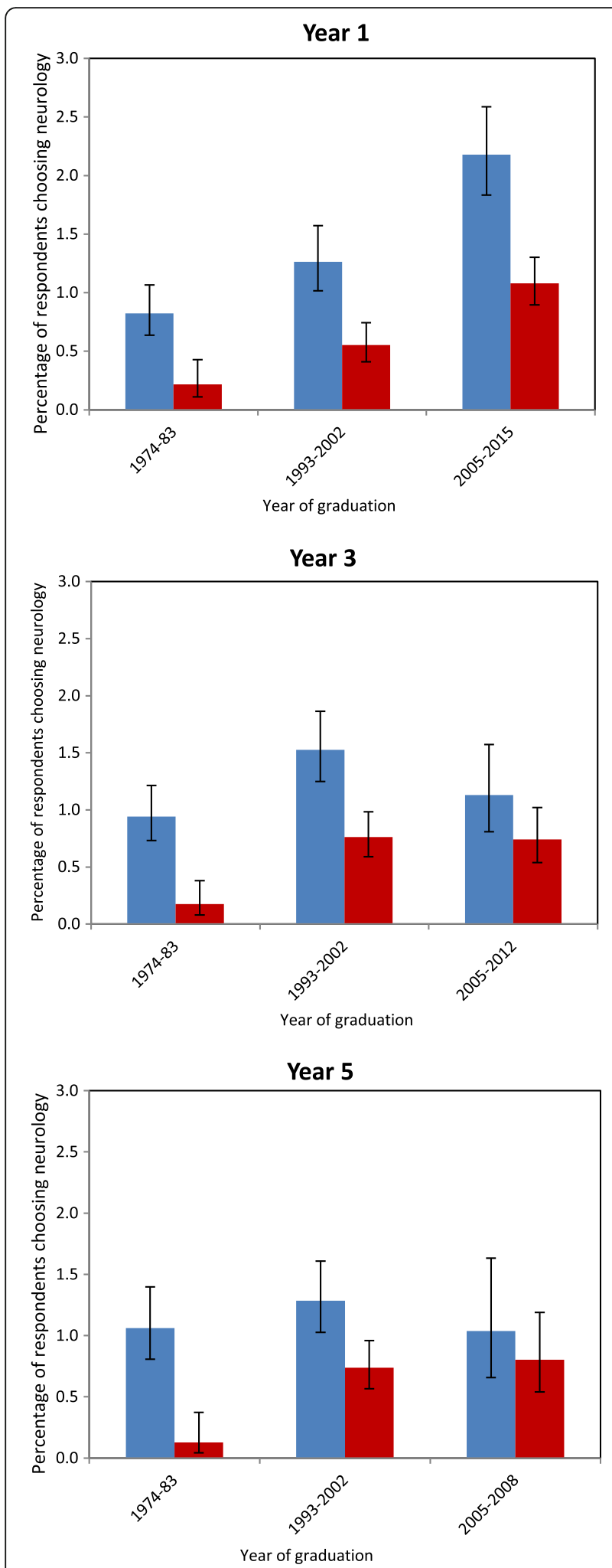

Fig. 1 Choosing neurology as first choice of eventual career in year 1,3 , and 5 after graduation
"Student experience of subject" and "inclinations before medical school" were the only factors to be consistently rated as significantly $(p<.001)$ more important to intending neurologists than other hospital physician specialists, in all three survey years.

We compared the scoring of importance of the factors by men and women who chose neurology (results not shown). Female doctors who considered neurology as a career were more concerned than their male peers about "wanting a career that fits my domestic situation" at year 1 after graduation $(p=0.006$, $\left.x^{2}=7.6\right)$. In comparison, at year 3 , "career and promotion prospects" were more important for men who had specified neurology as a first choice than for women $\left(p=0.001, x^{2}=11.3\right)$. Further analysis of all factors did not show any other significant differences between male and female intending neurologists.

\section{Specialty destination}

Ten years after graduation, the doctors from the cohorts of 1993 to 2002 were categorized according to whether they were now practicing neurologists (Tables 4 and 5 ).

Looking 'forward' from early choices to career destinations (Table 4), 39.4\% of those who chose neurology as a first choice in year 1 were working as neurologists in year 10 , compared with $62.8 \%$ for year 3 choices and $86.9 \%$ for year 5 choices. Gender differences were significant: in each year proportionately fewer of the women than the men who chose neurology in year 1 worked in the specialty later, and even for those who at year 5 intended to be neurologists a quarter of women were not working in it five years later (Table 4).

Looking 'backwards' from career destinations ten years after graduation to earlier choices (Table 5), of those working in neurology at year 10 , more than a quarter $(27.7 \%)$ had specified it as their sole first choice in year 1 ; but this percentage increased substantially at year 3 and reached over three-quarters (75.8\%) when year 5 choices were considered. The same trend was observed for males and females: $X^{2}{ }_{1}$ tests, comparing the percentage of men and women neurologists who had made it a first choice in each of years 1,3 , and 5 , gave nonsignificant results $(p=.07, .056, .570$ respectively). The percentage of practising neurologists who had chosen other hospital physician specialties in year 1 was $37.0 \%$ compared with $6.8 \%$ when year 5 choices were considered.

\section{Discussion}

The context of specialist training in neurology in the UK and the US

Presently, specialty training in neurology in the UK takes five years, one of which may be relevant research. Entry 
Table 2 Certainty of career choice by specialty chosen one, three and five years after graduation: numbers (N) and percentages (\%) of respondents

\begin{tabular}{|c|c|c|c|c|c|}
\hline \multirow[b]{2}{*}{ Year after graduation } & \multirow[b]{2}{*}{ Specialty choice } & \multicolumn{4}{|c|}{ Level of certainty about career choice } \\
\hline & & $\begin{array}{l}\text { Definite } \\
\mathrm{N}(\%)\end{array}$ & $\begin{array}{l}\text { Probable } \\
\mathrm{N}(\%)\end{array}$ & $\begin{array}{l}\text { Uncertain } \\
\mathrm{N}(\%)\end{array}$ & $\begin{array}{l}\text { Total } \\
\mathrm{N}(\%)\end{array}$ \\
\hline \multirow[t]{2}{*}{ Year 1} & Neurology & $81(19.7)$ & $236(57.4)$ & $94(22.9)$ & $411(100)$ \\
\hline & Other hospital physician specialties & $1191(12.7)$ & $4663(49.9)$ & $3498(37.4)$ & $9352(100)$ \\
\hline \multirow[t]{2}{*}{ Year 3} & Neurology & $93(32.9)$ & $133(47.0)$ & $57(20.1)$ & $283(100.0)$ \\
\hline & Other hospital physician specialties & $1220(25.3)$ & $2363(49.1)$ & $1233(25.6)$ & $4816(100.0)$ \\
\hline \multirow[t]{2}{*}{ Year 5} & Neurology & $149(67.4)$ & $59(26.7)$ & $13(5.9)$ & $221(100.0)$ \\
\hline & Other hospital physician specialties & $2079(60.7)$ & $1074(31.4)$ & $270(7.9)$ & $3423(100.0)$ \\
\hline
\end{tabular}

$X_{2}^{2}$ test results, comparing those who chose neurology with those who chose other hospital physician specialties: Year $1 X_{2}^{2}=41.8, p<.001 ; Y e a r 3 X_{2}^{2}=9.3$, $p=.010$; Year $5 x^{2}{ }_{2}=4.1, p=.132$

In this paper "other hospital physician specialties" comprises general medicine, cardiology, dermatology, endocrinology, geriatrics, nephrology, chest medicine, rheumatology/rehabilitation, academic medicine, genito-urinary medicine (or venereology), gastroenterology, vascular medicine, tropical medicine, clinical pharmacology, infectious diseases, occupational medicine (or industrial medicine)

into neurology training is possible following successful completion of a two-year postgraduate foundation programme, followed by a three-year core training programme. There are two core training programmes in the UK which are relevant to neurology training: Core Medical Training, and Acute Care Common Stem Acute Medicine. A fully qualified neurologist in the UK will therefore have completed an undergraduate medical degree of typically three to five years in duration, a two year postgraduate foundation, a three year core training, and a five-year specialist neurology training, a total of some 13-15 years. In the context of our study, at year 1 we surveyed doctors in their first foundation year, in year 3 in their first year of core training, and in year 5 at the end of core training, as they make a commitment to a particular specialty in which to complete their training.

For comparison, the training system in the US is broadly similar, though there are terminological differences. Typically, a four year medical degree would be followed by a one to three-year internship in internal medicine then followed by 5 to 7 years of specialist training in neurology.

\section{Main findings of this study}

The popularity of neurology was higher one year after graduation among recent medical graduates (20052015) than among their predecessors; nevertheless,

Table 3 UK doctors who specified each factor as influencing their choice of career "a great deal"

\begin{tabular}{|c|c|c|c|c|c|c|}
\hline \multirow[t]{2}{*}{ Factor influencing career choice } & \multicolumn{2}{|l|}{ Year 1} & \multicolumn{2}{|l|}{ Year 3} & \multicolumn{2}{|l|}{ Year 5} \\
\hline & $\begin{array}{l}\text { Neurology } \\
\text { N (\%) }\end{array}$ & $\begin{array}{l}\text { Other hospital } \\
\text { physician specialties } \\
\mathrm{N}(\%)\end{array}$ & $\begin{array}{l}\text { Neurology } \\
\text { N (\%) }\end{array}$ & $\begin{array}{l}\text { Other hospital } \\
\text { physician specialties } \\
\mathrm{N}(\%)\end{array}$ & $\begin{array}{l}\text { Neurology } \\
\text { N (\%) }\end{array}$ & $\begin{array}{l}\text { Other hospital physician } \\
\text { specialties } \\
\text { N (\%) }\end{array}$ \\
\hline Domestic situation & $62\left(19.5^{*}\right)$ & $1738(24.9)$ & $36\left(17.6^{*}\right)$ & 801 (23.6) & $53(24.2)$ & $921(28.0)$ \\
\hline Hours/working conditions & $79(27.9)$ & 1925 (31.9) & $68\left(48.2^{* *}\right)$ & $806(36.3)$ & $69(41.6)$ & $1027(39.9)$ \\
\hline Future financial prospects & $14(6.0)$ & $455(8.4)$ & $8(5.7)$ & $192(8.6)$ & $9(5.4)$ & $208(8.0)$ \\
\hline Financial circumstances whilst training & $4\left(11.8^{* *}\right)$ & $30(3.1)$ & $3(3.0)$ & $85(5.3)$ & $5(6.7)$ & $69(6.0)$ \\
\hline Career/promotion prospects & $48(17.9)$ & $1282(20.1)$ & $48(28.2)$ & $833(28.8)$ & $53(24.0)$ & $856(25.9)$ \\
\hline Self-appraisal & $132(49.3)$ & $2927(45.8)$ & $119(58.3)$ & $1855(54.8)$ & $121(55.0)$ & $1885(57.0)$ \\
\hline Advice from others & $25\left(9.3^{* *}\right)$ & $997(15.6)$ & $29(17.2)$ & $584(20.2)$ & $38(17.2)$ & $546(16.5)$ \\
\hline Student experience of subject & $161\left(50.6^{* * *}\right)$ & $2590(37.0)$ & $71\left(39.0^{* * *}\right)$ & $814(25.6)$ & $76\left(37.4^{* * *}\right)$ & $701(22.5)$ \\
\hline Particular teacher/department & $90\left(33.6^{* *}\right)$ & $1679(26.3)$ & $62(42.2)$ & $984(36.1)$ & $66(36.5)$ & $1028(38.2)$ \\
\hline Inclinations before medical school & $44\left(16.4^{* * *}\right)$ & $501(7.8)$ & $39\left(21.5^{* * *}\right)$ & $220(6.9)$ & $28\left(13.9^{* * *}\right)$ & $197(6.3)$ \\
\hline Experience of jobs so far & $77\left(33.0^{* * *}\right)$ & $2794(51.3)$ & $113(55.1)$ & $1973(58.5)$ & $140(63.6)$ & $2163(65.4)$ \\
\hline Enthusiasm/commitment & $183\left(64.9^{*}\right)$ & $3473(57.9)$ & $100(71.9)$ & $1540(69.6)$ & $136(81.4)$ & $2071(80.1)$ \\
\hline Other reasons & $22\left(16.4^{* *}\right)$ & $249(9.1)$ & $14(14.3)$ & $263(18.0)$ & $24(26.1)$ & $268(23.9)$ \\
\hline
\end{tabular}


Table 4 Career destinations at 10 years of doctors who expressed a career preference for neurology in years 1, 3, or 5

\begin{tabular}{|c|c|c|c|c|}
\hline & \multicolumn{4}{|c|}{ Year 10 destinations } \\
\hline & $\begin{array}{l}\text { Neurology } \\
\text { N (\%) }\end{array}$ & $\begin{array}{l}\text { Other hospital physician specialties } \\
\text { N (\%) }\end{array}$ & $\begin{array}{l}\text { Others } \\
N(\%)\end{array}$ & $\begin{array}{l}\text { All destinations } \\
\mathrm{N}(\%)\end{array}$ \\
\hline \multicolumn{5}{|l|}{ Year 1 1st choices } \\
\hline Men choosing neurology & $29(47.5)$ & $16(26.2)$ & $16(26.2)$ & $61(100.0)$ \\
\hline Women choosing neurology & $8(24.2)$ & $13(39.4)$ & $12(36.4)$ & $33(100.0)$ \\
\hline Total choosing neurology & $37(39.4)$ & $29(30.9)$ & $28(29.8)$ & $94(100.0)$ \\
\hline \multicolumn{5}{|l|}{ Year 3 1st choices } \\
\hline Men choosing neurology & $54(70.1)$ & $10(13.0)$ & $13(16.9)$ & $77(100.0)$ \\
\hline Women choosing neurology & $22(50.0)$ & $12(27.3)$ & $10(22.7)$ & $44(100.0)$ \\
\hline Total choosing neurology & $76(62.8)$ & $22(18.2)$ & $23(19.0)$ & $121(100.0)$ \\
\hline \multicolumn{5}{|l|}{ Year 5 1st choices } \\
\hline Men choosing neurology & $61(95.3)$ & $0(0.0)$ & $3(4.7)$ & $64(100.0)$ \\
\hline Women choosing neurology & $32(74.4)$ & $5(11.6)$ & $6(14.0)$ & $43(100.0)$ \\
\hline Total choosing neurology & $93(86.9)$ & $5(4.7)$ & $9(8.4)$ & $107(100.0)$ \\
\hline
\end{tabular}

unlike earlier cohorts, as more time passes from their graduation, the level of attraction towards neurology fell among these young graduates. Among those who chose neurology in year 1 , certainty about their choice was higher than among those who chose other hospital physician specialties, but this difference reduced in years 3 and 5. High competition ratios for neurology residency positions (four candidates per specialty training post has been quoted in 2016) [17] or more appealing conditions of

Table 5 Original career choices in years 1, 3, and 5 of doctors practising as neurologists in year 10

\begin{tabular}{|c|c|c|c|}
\hline Career choices & $\begin{array}{l}\text { Male } \\
\text { N (\%) }\end{array}$ & $\begin{array}{l}\text { Female } \\
\mathrm{N}(\%)\end{array}$ & $\begin{array}{l}\text { Total } \\
\text { N (\%) }\end{array}$ \\
\hline \multicolumn{4}{|l|}{ Year 1} \\
\hline Neurology untied 1st choice & $23(32.3)$ & $7(18.9)$ & $30(27.7)$ \\
\hline Neurology tied 1st choice & $6(8.4)$ & $1(2.7)$ & $7(6.4)$ \\
\hline Neurology 2nd or 3rd choice & $7(9.8)$ & $3(8.1)$ & $10(9.2)$ \\
\hline Any choice for other hospital physician specialties & $26(36.6)$ & $14(37.8)$ & $40(37.03)$ \\
\hline Other choices & $9(12.6)$ & $12(32.4)$ & $21(19.4)$ \\
\hline Total & $71(100.0)$ & $37(100.0)$ & $108(100.0)$ \\
\hline \multicolumn{4}{|l|}{ Year 3} \\
\hline Neurology untied 1st choice & $47(70.1)$ & $20(55.5)$ & $67(65.04)$ \\
\hline Neurology tied 1st choice & $7(10.4)$ & $2(5.5)$ & $9(8.7)$ \\
\hline Neurology 2nd or 3rd choice & $2(2.9)$ & $2(5.5)$ & $4(3.8)$ \\
\hline Any choice for other hospital physician specialties & $7(10.4)$ & $6(16.6)$ & $13(12.6)$ \\
\hline Other choices & $4(5.9)$ & $6(16.6)$ & $10(9.7)$ \\
\hline Total & $67(100.0)$ & $36(100.0)$ & $103(100.0)$ \\
\hline \multicolumn{4}{|l|}{ Year 5} \\
\hline Neurology untied 1st choice & $56(75.6)$ & $32(76.1)$ & $88(75.8)$ \\
\hline Neurology tied 1st choice & $5(6.7)$ & $0(0.0)$ & $5(4.3)$ \\
\hline Neurology 2nd or 3rd choice & $7(9.4)$ & $3(7.1)$ & $10(8.6)$ \\
\hline Any choice for other hospital physician specialties & $5(6.7)$ & $3(7.1)$ & $8(6.8)$ \\
\hline Other choices & $1(1.3)$ & $4(9.5)$ & $5(4.3)$ \\
\hline Total & $74(100.0)$ & $42(100.0)$ & $116(100.0)$ \\
\hline
\end{tabular}

Data are for neurologists at ten years after medical school graduation (1993, 1996, 1999, 2000, 2002 cohorts) 
work in other specialties might underpin the above trends.

This paper found neurology to be a maledominated specialty, in all cohorts and years from graduation, although there was some evidence from the most recent cohorts surveyed at year 5 that the gender difference may be reducing. Having chosen neurology, women were less likely than men to convert their choice into a career in neurology; and, even as late as five years after graduation, women specifying neurology as their first choice were less likely than men to be working in the field five years later. Gender imbalance in medical specialties and particularly in neurology was frequently reported in other national and international studies [10, 18, 19]. One possible explanation for this can be the perceived difficulty to maintain work-life balance among neurologists [10] and stereotypical assumptions about what women should do [20]. As the family life of female doctors is more affected than that of male doctors by their work [20, 21], the reported gender differences are to some degree understandable.

The correspondence between early career choices and eventual specialty destinations was quite strong for neurology, especially for men, but not as strong as other specialties. For example, 39\% of those who chose neurology in year 1 were neurologists in year 10. As comparisons in other specialties, $82 \%$ of doctors who chose general practice in year 1 were general practitioners in year $10 ; 75 \%$ who chose psychiatry in year 1 were psychiatrists in year 10 . Conversely, $30 \%$ of practising neurologists had chosen neurology as their preferred career in year 1; $50.0 \%$ of practising GPs in year 10 had chosen general practice as their preferred career in year 1 ; and $52 \%$ of practising psychiatrists had specified psychiatry as their preferred career choice in year 1 [22]. Thus, all these specialties were boosted by 'late converters', doctors who did not choose the specialties in the early years but who eventually practised in them.

Decisions about neurology as an eventual career were still uncertain in a quarter of cases five years after graduation. This problem was similarly reported in other medical specialties such as cardiology [14] and results in late decisions to commit a career. It may be appropriate for decisions to commit to individual specialties within physician practice to be deferred; but this is a matter for discussion and decision within the profession. Consideration should be given to whether late decision-making might be attributed to the lack of knowledge about the reality of working in a specialty (in this case neurology) among medical graduates and insufficient support for them to choose a career that best matches their aptitude and willingness [7].

In this study, "enthusiasm/commitment", "student experience of subject", "experience of jobs so far", and "self-appraisal" were identified as the most influential factors which can inspire medical graduates to neurology. It is notable that the first two factors were also emphasised by our participants who intended to pursue other hospital physician specialties. Since core professional training for neurology and other hospital physician specialties is the same [23], it is rational that their applicants have common motivations and inspirations.

Advantages of close agreement between early choices and later destinations in neurology are that early specialist training programmes can be organised in the expectation that early choosers will hold their enthusiasm and fascination for the specialty in the longer term; and that, if past performance is a guide to future opportunities, that they will be successful in getting jobs in the specialty. A case against early specialist training programmes confined to neurology is that they may reduce future career options, if needed, in other branches of specialist physician practice. These are issues for consideration by trainers, trainees and educational planners within neurology and general physician practice.

\section{Implications}

This paper offers insights into neurology career choices and progression through examining its recruitment trends, gender differences in the specialty, influencing factors on career decision, and the matching of original choices and later career destinations among practising neurologists. As the data reveal, neurology holds greater appeal for recent medical graduates than their predecessors. It is important to maintain this trend and increase its rate over the coming years to meet the current and future needs of neurological patients. In recent years, the number of female doctors choosing neurology as their future career has significantly increased but the gender gap still persists. Adopting some innovative policies may tackle this gender imbalance in the specialty and help female doctors reach their full potential. Such policies may include encouraging family friendly benefits, offering paid parental leave, and flexible working hours [24].

Study findings about influencing factors are in line with previous studies that highlighted the importance of interest and fascination [11], and prior experience factors $[7,10]$ for intending neurologists. The inherent interest and fascination factor, usually regarded as "good fit", is an intangible element [11] and can be 
shaped through the effect of other elusive factors. None of the previous work has examined the impact of this factor on medical students' thinking regarding their career choice. Therefore, further studies are required to provide a more sophisticated and in-depth exploration of its components and compare them between neurology and other specialties.

Addressing late career decisions by improving mentorship programmes may be one strategy to accelerate the career decision process and subsequently promote satisfaction and retention for intending neurologists. The programme should embed early socialization strategies such as job-shadowing to provide realistic and contemporary portrayals of neurology practice and enhance the applicants' understanding of their future practice roles and care environment [25]. CORTEX (Comprehensive Opportunities for Research and Teaching Experience) developed by Zuzuárregui and Hohler in the US is an example of a successful longitudinal mentorship programme that constitutes a consistent interaction between students and mentors to increase the exposure of students to neurology through teaching and research [26]. Further research is suggested to design a practice development plan for medical students which focuses on individuals' abilities while considering contextual variables $[27,28]$.

\section{Limitations and strengths}

Despite the high overall response rate of the study, non-response bias is possible.

This is a unique, large-scale, national, and multicohort study in the UK that captured the views and aspirations of medical graduates over many years (1974-2015). It has produced a big database of information which can be applied for generating evidence relevant to policies and planning in other individual specialties regarding medical training and doctors' recruitment in the UK health care system.

\section{Conclusions}

This paper adds to the available information on neurology careers in the UK. The study findings should be helpful for medical graduates considering neurology for their eventual career as well as education providers, decision makers, commissioners of services, workforce planners and other stakeholders. The latter can consider the implications of this paper and use them in preparing and supporting medical graduates for their future careers. These may help in planning service provision and the supply of an adequate professional workforce for people affected by neurological conditions in the UK.

\section{Appendix}
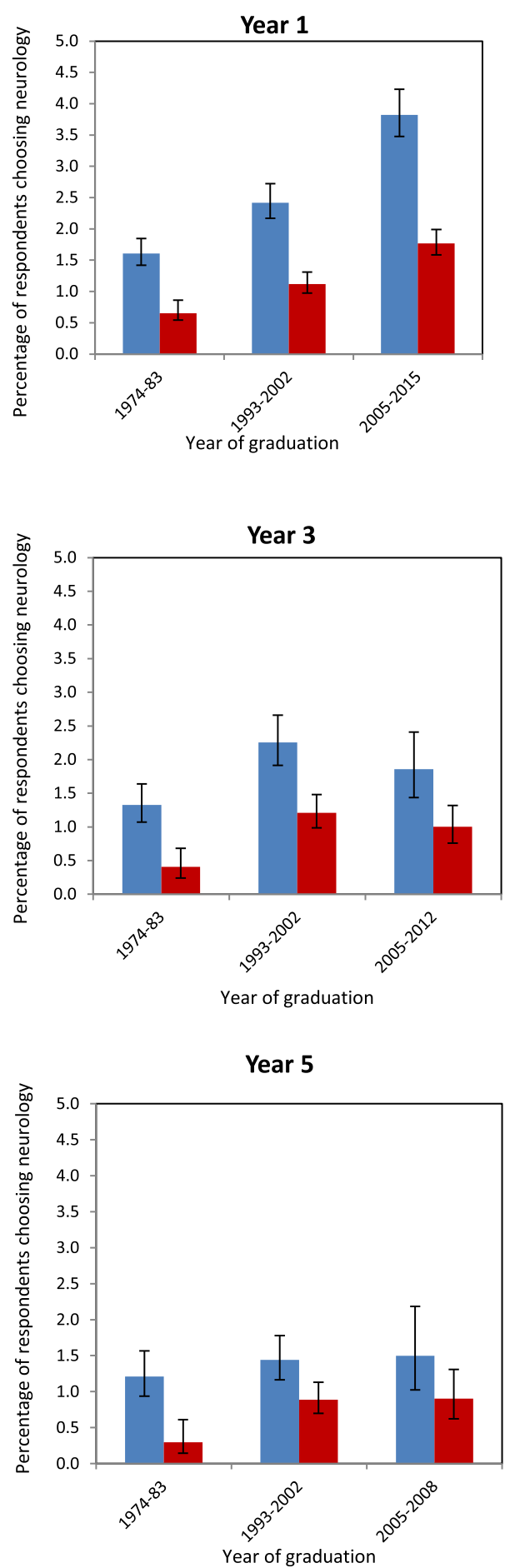

Fig. 2 Choosing neurology as any choice of eventual career in year 1,3 , and 5 after graduation 


\section{Additional file}

Additional file 1: Table S1. Choices for neurology in individual recent cohorts: percentages and numbers of responders. (DOCX $16 \mathrm{~kb}$ )

\section{Abbreviations}

Cl: Confidence interval; CORTEX: Comprehensive Opportunities for Research and Teaching Experience; GMC: General Medical Council; GP: General practitioner (family doctor); NHS: National Health Service of the United Kingdom; UK: United Kingdom; US: United States of America

\section{Acknowledgements}

We thank Ritva Ellison for data management and Alison Stockford for data entry. We are very grateful to all the doctors who participated in the surveys.

\section{Authors' contributions}

$T L$ and MJG designed and conducted the surveys. AB performed the analysis and wrote the first draft of the paper. All authors contributed to further drafts and all approved the final version. All authors are guarantors.

\section{Funding}

This report is based on independent research commissioned and funded by the NIHR Policy Research Programme (Cohort Studies of Doctors' Careers, project 016/0118). The views expressed in the publication are those of the author(s) and not necessarily those of the NHS, the NIHR, the Department of Health, its arms' length bodies or other government departments.

\section{Availability of data and materials}

The datasets generated and/or analysed during the current study are not publicly available due to reasons of practicality. It may be possible for the authors to make tabulated data, produced in the course of this work but not included in the paper, available to interested readers on request.

\section{Ethics approval and consent to participate}

Obtained from the National Research Ethics Service, following referral to the Brighton and Mid-Sussex Research Ethics Committee in its role as a multi-centre research ethics committee (ref 04/Q1907/48 amendment Am02 March 2015).

\section{Consent for publication}

Not applicable.

\section{Competing interests}

All authors have completed the Unified Competing Interest form at http:// www.icmje.org/conflicts-of-interest/ (available on request from the corresponding author) and all authors want to declare: (1) financial support for the submitted work from the policy research programme, Department of Health. All authors also declare: (2) no financial relationships with commercial entities that might have an interest in the submitted work; (3) no spouses, partners, or children with relationships with commercial entities that might have an interest in the submitted work; (4) no non-financial interests that may be relevant to the submitted work.

\section{Received: 24 October 2017 Accepted: 4 June 2019}

\section{Published online: 10 July 2019}

\section{References}

1. Pickersgill T. A career in neurology. BMJ. 2004:329. https://doi.org/10.1136/ bmj.329.7465.s93-a. Published 04 September 2004

2. Hachinski V. Careers in neurology in a globalizing world. Neurology. 2016; 86(2):e21-3.

3. World Health Organisation. World Federation of Neurology: atlas country resources for neurological disorders. 2nd ed. Geneva: World Health Organisation; 2017

4. Federation of the Royal Colleges of Physicians of the UK. Census of consultant physicains and higher specialty trainees in the UK 2014-15. In:

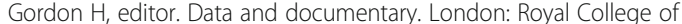
Physicians; 2016

5. Dall TM, Storm MV, Chakrabarti R, Drogan O, Keran CM, Donofrio PD, Henderson WW, Kaminski HJ, Stevens JC, Vidic TR. Supply and demand analysis of the current and future US neurology workforce. Am Academy Neurol. 2013:81(5):470-8.

6. Albert DV, Hoyle C, Yin H, McCoyd M, Lukas RV. Why neurology? Factors which influence career choice in neurology. Neurol Res. 2016:38(1):10-4.

7. Kamour AH, Han DY, Mannino DM, Hessler AB, Kedar S. Factors that impact medical student and house-staff career interest in brain related specialties. J Neurol Sci. 2016;15(369):312-7.

8. Larsen DP, Santini VE. Increasing student recruitment into neurology: joining the family. Neurology. 2015;84(23):2302-3.

9. Lee $\mathrm{JH}, \mathrm{Kim} \mathrm{Gl}$, Park KH, Yune SJ. Differences in factors affecting medical specialty choices between medical college students and graduate medical school students. Korean J Med Educ. 2009;21(4):393-402.

10. Pakpoor J, Handel AE, Disanto G, Davenport RJ, Giovannoni G, Ramagopalan SV. Association of British N: national survey of UK medical students on the perception of neurology. BMC Med Educ. 2014;14:225.

11. Humbert KA, Chang BS. In the beginning: how medical students choose (or do not choose) neurology. Ann Neurol. 2014;75(4):487-9.

12. Emmanouil B, Goldacre M, Lambert T. Aspirations to become an anaesthetist: longitudinal study of historical trends and trajectories of UKqualified doctors' early career choices and of factors that have influenced their choices. BMC Anesthesiol. 2017;17:100.

13. Goldacre M, Laxton L, Harrison E, Richards J, Lambert T, Parks R. Early career choices and successful career progression in surgery in the UK: prospective cohort studies. BMC Surg. 2010;10:32

14. Smith F, Lambert T, Pitcher A, Goldacre M. Career choices for cardiology: cohort studies of UK medical graduates. BMC Medical Education. 2013:13:10

15. Goldacre M, Lambert T. Participation in medicine by graduates of medical schools in the United Kingdom up to 25 years post graduation: National Cohort Surveys. Acad Med. 2013;88(5):699-709.

16. Corp IBM. IBM SPSS statistics for windows. In: 22.0 edn. Armonk: IBM Corp; 2013

17. Health Education England: Competition Ratios 2017. Dowloadable from https://specialtytraining.hee.nhs.uk/Competition-Ratios.

18. Svirko E, Lambert T, Goldacre M. Career progression of men and women doctors in the UK NHS: a questionnaire study of the UK medical qualifiers of 1993 in 2010/2011. J Royal Soc Med Open. 2014;5(11):1-9.

19. Arizabalaga P, Abellanac R, Vinas O, Merinoe A, Ascaso C. Gender inequalities in the medical profession: are there still barriers to women physicians in the 21st century? Gac Sanit. 2014;28(5):363-8.

20. Linehan C, Sweeney C, Boylan G, Meghen K, O' Flynn S. Getting in and getting on in medical careers: how the rules of the game are gendered. Gender, Sexuality \& Feminism. 2013;1(1):18-36.

21. Carroll CB, Tengah DS, Lawthom C, Venables $G$. The feminisation of British neurology: implications for workforce planning. Clinical Medicine. 2007;7(4): 339-42.

22. Goldacre M, Laxton L, Lambert T. Medical graduates' early career choices of specialty and their eventual specialty destinations: UK prospective cohort studies. Br Med J. 2010;341(c3199):1-9.

23. Joint Royal Colleges of Physicians Training Board. Specialty training curriculum for neurology. London: General Medical Council; 2013.

24. Wehner M, Nead K, Linos K, Linos E. Plenty of moustaches but not enough women: cross sectional study of medical leaders. Br Med J. 2015:351:h6311.

25. Price S. Becoming a nurse: a meta-study of early professional socialization and career choice in nursing. J Adv Nurs. 2009;65(1):11-9.

26. Zuzuárregui J, Hohler A. Comprehensive opportunities for research and teaching experience (CORTEX): a mentorship program. Neurology. 2015 84(23):2372-6.

27. Canales A. Degree completion in the UK: individual, institutional and contextual factors that explain students' chances of educational success in British universities. Oxford: University of Oxford; 2013.

28. Abery B, Stancliffe R. An ecological theory of self-determination: Theoretical foundations. In: Wehmeyer M, Abery B, Mithaug D, Stancliffe R, editors. Theory in self-determination: Foundations for educational practice. Springfield: Charles C Thomas Publisher; 2003. p. 25-42.

\section{Publisher's Note}

Springer Nature remains neutral with regard to jurisdictional claims in published maps and institutional affiliations. 